\title{
Individuals with traumatic brain injuries perceptions and experiences of returning to work in South Africa
}

\author{
Mogammad Shaheed Soeker, Viki Van Rensburg and Andre Travill
}

\begin{abstract}
Objective: The aim of this study was to identify the central concepts of a model that would facilitate the return to work process of individuals with brain injury. However for the purpose of this paper there will be a focus only on the barriers and facilitators that influence the return to work process.

Participants: Ten individuals who were diagnosed with a mild to moderate brain injury participated in this study.

Methods: Qualitative research methods were used in order to explore the research question. The participants were selected by means of purposive sampling and the data was collected by means of in depth interviews.

Results: The results of the study revealed that the participants experienced a sense of loss of function after the brain injury, a fear of the future and loss of confidence in their worker roles. The participants also indicated that by means of adapting occupational routines an actively engaging in rehabilitation they developed confidence in their worker roles.

Conclusion: Occupational therapists have to use a client centred holistic work integrative approach in order to successfully rehabilitate as well as facilitate the return to work process with people who have suffered a traumatic brain injury.
\end{abstract}

\section{Introduction}

An increase in the numbers of individuals who sustained brain injuries due to motor vehicle accidents, trauma induced by violence and substance abuse, has resulted in more disabled individuals becoming non-productive members in society and inactive in the workplace $[1,2]$. Research in the field of brain injury rehabilitation in South Africa is limited, with the majority of research focusing on the medical model of intervention. In the medical model, the disabled or injured individual is regarded as having problems that require medical-biological intervention mainly, with little or no attention given to the difficult process of reintegrating the disabled individual back into society, for example, in resuming their worker roles [3]. The medical approach may result in feelings of disempowerment on behalf of the disabled with regard to the rehabilitation process $[3,4]$. The lack of success of current rehabilitation interventions could be seen as a result of an inability to generalize outcomes of rehabilitation in a clinical setting to the skills needed to return to work or re-integrate into the community. 
Statistics from an occupational therapy work assessment unit in a tertiary hospital revealed that $97 \%$ of clients with brain-injury, the majority suffering from either a mild or moderate brain injury, were found unfit to return to work in the open labour market in South Africa [5]. This is in contrast to statistics that suggest the possibility of an $84 \%$ return to work rate by individuals with brain-injuries in the United States of America [6]. One of the main concerns was the fact that these brain injured individuals were not fit to return to work in any occupation in the open labour market despite having undergone the necessary rehabilitation in either a private or public facility. Rehabilitation in this context consisted of occupational therapy, physiotherapy and speech therapy. The poor functional work abilities or skills revealed by the assessment results prompted the research and my desire to explore the perceptions and experiences of these individuals when resuming their worker roles. The intended outcome will be to utilise the participants' experiences as a basis in order to develop a model that would assist occupational therapists in reintegrating the brain injured individuals back into their worker roles.

\section{Epidemiology of traumatic brain injuries}

A traumatic brain injury can be defined as damage to the brain that occurs as a result of external forces such as accidents or assaults, thereby excluding neurological conditions such as cerebro-vascular accidents and degenerative brain diseases [7]. In contrast, non traumatic brain injuries are caused by drug overdose, chronic substance abuse, carbon monoxide poisoning, brain abscess, meningitis and encephalitis [8]. Most brain injuries occur during the years when people are aiming for vocational goals and acquiring skills. It affects people of all ages and is the leading cause of long term disability in young adults [9]. More males than females are affected with brain injuries at a ratio of approximately 2-2.5:1 [7]. In South Africa there was a 60\% increase in the number of mortalities due to brain injuries between 1997 and 2002 [10]. Statistics of one of the tertiary hospitals in the Western Cape reflect a 70\% increase in the number of patients admitted with brain injuries between 2003 and 2004 [11]. In 1998 alone, an amount of R 56971 148, 78 was paid to claimants with brain injuries as a result of their incapacity to work [12]. The above statistics indicates that there is a need for rehabilitation to be client centered with a focus on vocation goals in order to minimize the loss of productivity to the individual and the economy in general.

\section{Current rehabilitation approaches}

The cognitive rehabilitation system in South Africa advocates a system similar to that of North America [4]. Two of the major cognitive rehabilitation approaches are the remedial approach and the adaptive approach. The remedial approach is characterised by attempts to improve memory and perceptual skills [13]. The remedial approach is also referred to as the restorative approach focussing on attempting to remediate core areas of cognitive dysfunction by means of systematic training. A popular critique of this approach is that the amount of transference of the learned skill to functional settings is minimal [14]. 
The compensatory approach, which is also known as the adaptive approach, is generally geared toward the facilitation of activities of daily living [14]. This approach is characterised by internal compensatory strategies such as verbal description, rehearsing and mnemonics. Whereas the external compensatory approach is characterised by memory aids such as diaries, calendars and electronic cuing devises [14]. Critique of these approaches include that they offer therapeutic intervention during the early stages of recovery and that they fail to meet the client's needs in the later recovery process. Blundon and Smits [14] also state that there is no strong evidence supporting the effectiveness of either of these approaches in enhancing occupational performance. Neither approach is client centered, nor do they take the client's personal goals or expressed needs into consideration.

\section{Return to work programmes}

Holistic return to work programmes are normally described by three phases: strategies to aid daily living; guided occupational trials in vocational placement, and support for the maintenance of employment. Ben-Yishay, Silver, Piatsetsky and Rattok [6] investigated the return to work success rates of 94 participants who participated in a head trauma programme which utilised a holistic cognitive approach. The study results revealed a $63 \%$ return to competitive work at the levels (academic, skilled and unskilled).

Another return to work programme is supportive employment which is defined as competitive employment in an integrated setting with ongoing support services for people with the most severe disabilities [15]. Jones, Perkins and Born [16] further described supportive employment as programmes that promote self sufficiency and improve the quality of life of people with the disabilities by motivating them to pursue work.

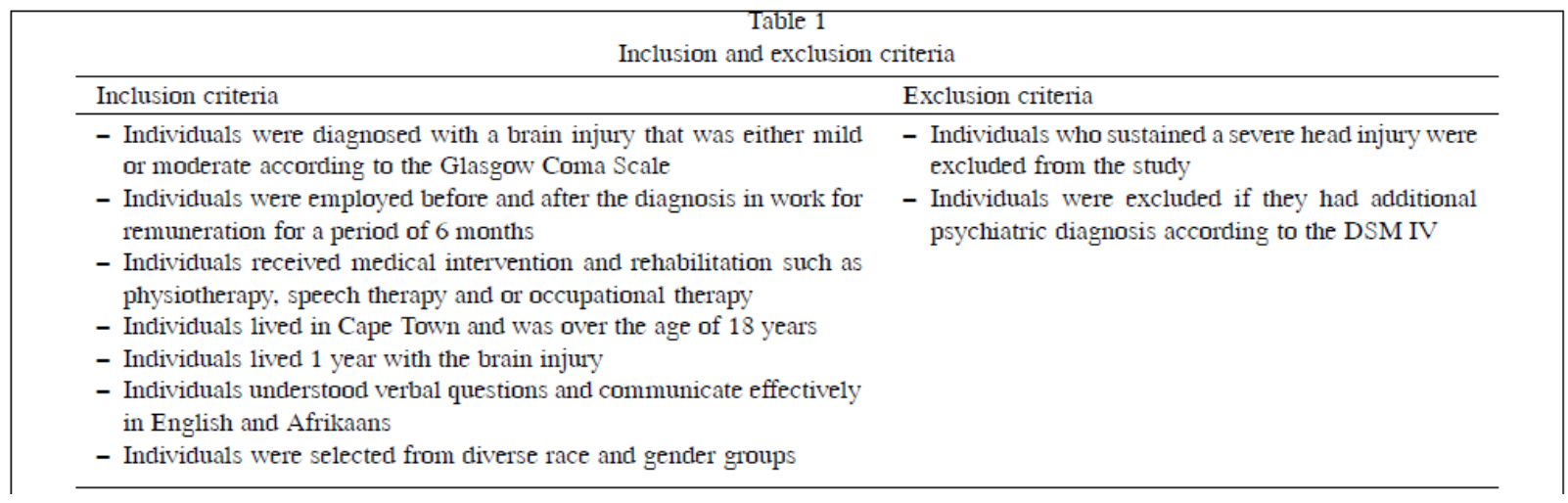

Wehman, West, Kregal, Sharron and Kreutzer [17] conducted a study utilising the supportive employment framework in which 87 participants participated. The results indicated that only $51.3 \%$ of the participants were employed after a period of 12 months. The above authors attributed the poor return to work rates to medical/health problems, economic lay off, slow/poor quality work, poor job match and inappropriate behaviour by the participants. 


\section{A need for studies exploring the personal perspectives of brain injured individuals}

Current research reveals a lack of studies that address the personal experience of individuals with brain injury when adapting to their worker role after rehabilitation. Johansson and Tham [18] indicate that one area in which there is a lack of knowledge is the meaning of work to people with brain injuries. Similarly, there are minimal occupational therapy studies that focus on the lived experience of individuals with brain injury [19]. The literature suggests that the quality of intervention programmes and services tend to be ineffective when the health professional does not take the individual with the brain injury's self identified needs into consideration, hence it needs to be client centred [19]. Therefore this study examined the experiences of people who sustained a traumatic brain... please just complete this statement with a transition before the RQ.

\section{Research question}

What is the "lived experience" for people with brain injury who have resumed their worker roles after brain injury rehabilitation?

\section{Aim}

To explore and describe the lived experience of people with brain injuries with regard to resuming their worker roles after the injury. Ultimately a model that will facilitate the return to work for clients with brain injury will be developed.

\section{Methods}

Qualitative research is fundamentally interpretive and includes a description of the individual, setting, analyzing data for themes and eventually drawing conclusions about its meaning [20]. It is also defined as a research approach that describes multiple realities and interpretations aimed at developing an in depth understanding of the perspectives of individuals [21]. Within the context of the current study a phenomenological research design was used as the researcher seeked to identify the experiences and perceptions of individuals with brain injury.

\section{Sampling}

In this study ten participants with brain injuries were selected through purposive sampling. Five participants were selected from the statistical records of Tygerberg Hospital's Occupational Therapy Department and five participants were selected from the Road Accident Fund Organization. The researcher analyzed the records at Tygerberg Hospital and the Road Accident Fund Organization utilizing the inclusion and exclusion criteria for participant selection. Table 1 describes the inclusion and exclusion criteria, Table 2 describe the demographic data of the participants. 


\section{Data collection}

An in-depth interview is defined as a technique to collect data through the interaction between an inter viewer and an interviewee in order to understand the complex behaviours of society [22].

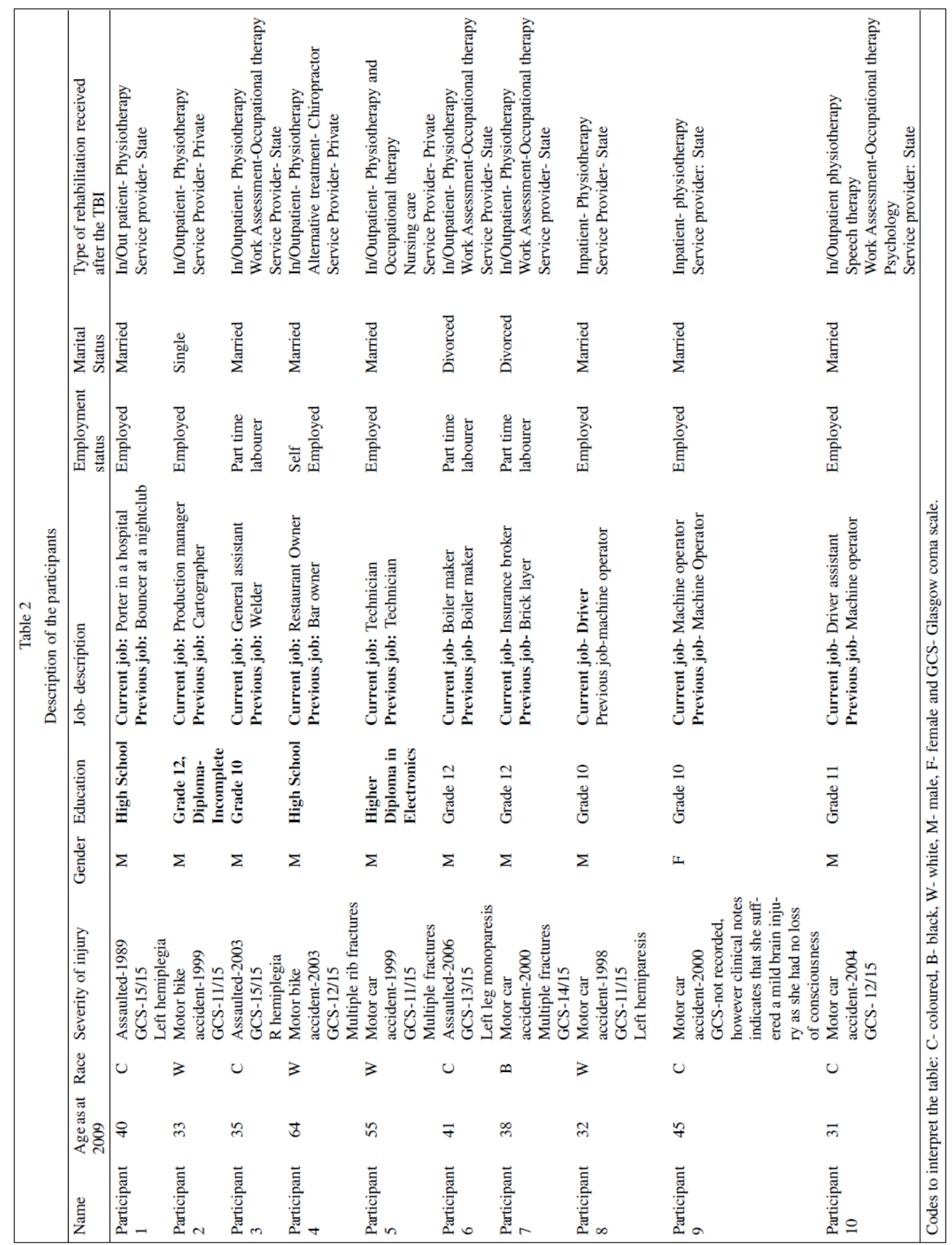

It also enables the researcher to gain an understanding of the meaning of experiences and events in peoples' lives [23]. Within this study the researcher utilized in depth 
interviews as a data collection method. Ten interviews including a pilot interview were conducted with participants during the period 01 January 2009 to 01 December 2009. The time periods of the interviews were 60 minutes on average. Interviews were conducted in the workplaces of two participants, interviews were conducted in the homes of six of the participants and two interviews were conducted at Tygerberg Hospital. Data were collected by means of audiotape-recording all the interviews. Simple participant observation was also utilized in order to describe the participant's non verbal behavior as well as the environment in which the participants lived and worked. The researcher also used simple participant observation that enabled him to observe the exterior of the participants' homes and workplaces; their expressive movements and language behaviour. The observation occurred in some of the participants' homes and workplaces of others. The researcher would spend on average 1.5 hours inclusive of the interviews in the participants' home or workplace. Their interactions with family and co workers were also recorded in the researcher's field notes. Audiotapes and field notes were transcribed in preparation for the analysis process.

\section{Data analysis}

The data were qualitatively analysed using the methods described by Morse and Field [24] i.e. comprehending, synthesizing (decontextualising), theorizing and recontextualising. A manual coding system to obtain codes, categories and themes was used. Phrases, words and statements that reflected a common phenomenon were identified as codes. Thereafter groups of codes were analysed for similarities or differences and then grouped into common categories. Thereafter the categories were further analysed to identify common relationships and links in order to develop themes. Strategies such as credibility, transferability, dependability and confirmability were used in order to ensure the trustworthiness of the data. Credibility was ensured by the dense description of the lived experience of the research participants. The descriptions of the lived experience of the participants were audio-recorded as they were talking and the audiotapes were transcribed verbatim to ensure that each participant's story was captured in their own narrative. Credibility was also ensured by means of member checking whereby a summary of the findings were reviewed by the participants in order to ensure its accuracy and triangulation. According to Duffy [25] triangulation is described as a means of establishing different patterns of agreement based on more than one method of observation, information gathering or the use of more than one data source in order to establish credibility. Within this study triangulation was ensured by the use of more than one method of collecting data, example, in depth interviews and simple participant observation. Each piece of data, when added to the previous data, strengthened or confirmed previous findings thus reinforcing the triangulation of the data. Transferability was ensured by the detailed description of the research methods, contexts, detailed description of the participants and the lived experience of participants that was made explicit. Dependability was ensured by means of dense descriptions of the experiences of the participants, peer examination and triangulation. The study was documented in such a manner that the readers could follow a decision trail. Finally confirmability was 
ensured by the process of reflexivity whereby the researcher's own biases or assumptions were made apparent by means of a reflexive journal. In the current study the research findings were purely from the perspective of the participants.

\section{Ethics}

The study was approved by the Ethics Committee of the University of the Western Cape (Ethics approval reference number 08/1/2). Informants were telephonically contacted whereby the aim, purpose and process of the study were explained to them. The details with regard to the study together with the consent forms were fully disclosed to the participants on their arrival at the interview session. All the participants gave their written consent to participate in the study as well as to have the findings of the study published in journals.

\section{Findings}

"A sense of loss of former self" and "Uncertainty about the future" were the two themes that presented the participant's perceptions of barriers that influenced the return to work process. "Participation in occupation enables growth" was seen as the theme that presented the participants' perceptions of facilitators that enabled them to return to work. The diagrammatic framework (see Fig. 1) indicates how the themes were interrelated, the participants viewed the absence of a facilitator to be a barrier and inversely the absence of a barrier was viewed to be a facilitator.

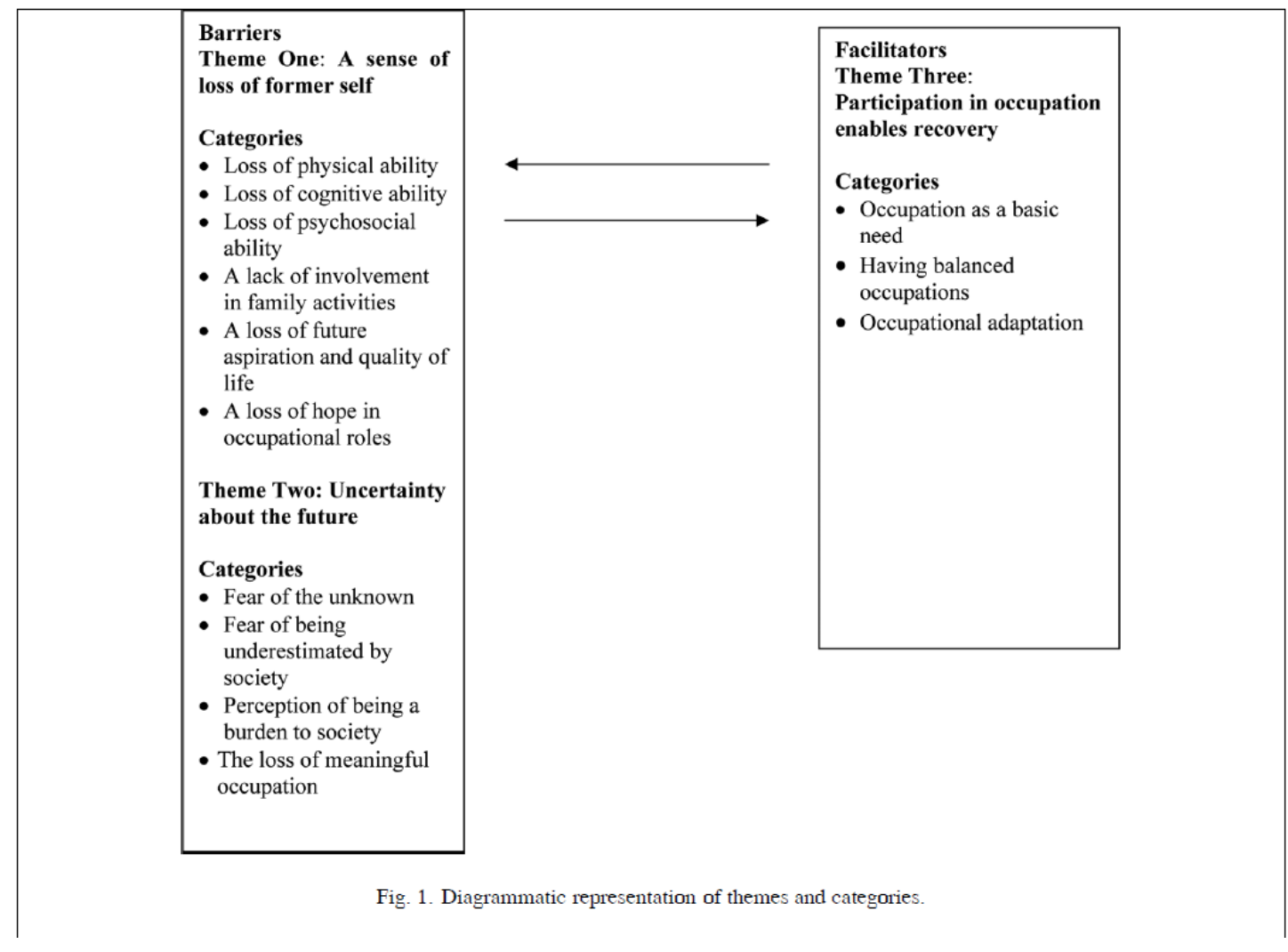




\section{Theme one: A sense of loss of former self (Barriers)}

Theme one, "A sense of loss of former self" was interpreted as a barrier. In the current study these losses were perceived by the participants as consisting of a combination of physical, cognitive and psychosocial losses.

\section{Loss of physical ability}

These physical losses often impacted on the individual's ability to engage in occupations such as self care activities, leisure activities and work activities. The physical limitations ranged from an inability to walk, attend to self care, participate in leisure and work related activities. These physical limitations reinforced the negative effects of the brain injury. As one participant explained:

I had just about every bone in my body broken, I was blind for nearly a year and half, I nearly lost my building (home and business premises) ( $\mathrm{P} 4$ ).

Another participant indicated that he struggled to do tasks that required flexion of the upper limb owing to poor muscular endurance. He explained:

And you've got to sort of adapt I mean I can't lift my hand up for too long otherwise it gets tired (P2.)

\section{Loss of cognitive ability}

The participants in this study often referred to their inability to concentrate for long periods of time. One participant reflected about the concentration difficulties he experienced in the workplace. The cognitive limitations ranged from memory loss, loss of contact with reality, loss of insight and a loss of self confidence. He indicated that he could not concentrate for long periods of time particularly when doing complicated tasks. He said:

It is a little difficult to think, but what I realised was that my concentration was definitely weaker. It was difficult for me to concentrate on something that was complicated, especially when it comes to the software of a computer. It was really difficult for me to concentrate, yes, I would say concentration. It remains a barrier for me ( $\left.\mathrm{P}_{5}\right)$.

\section{Loss of psychosocial ability}

The participants in this study all reported to have a low self confidence after the brain injury particularly when they resumed their previous roles. The loss of psychosocial ability ranged from a loss of self confidence, loss of self concept, loss of sexuality, and a lack of involvement in family activities. One participant indicated that his confidence was negatively affected when his employer mentioned that his productivity as a brick layer was not satisfactory: 
You are perfect in the job but your pace is very slow and you can't make production... They ask what has happened to you. Then they say, sorry man $\left(\mathrm{P}_{7}\right)$.

Another participant indicated that he felt demoralized as his employer had removed him from his previous job and placed him in a job that was less meaningful.

I will not come back. This is why I say, I am not proud of my work. No, I will not help anymore, understand. I felt that I wanted to tell him (employer), you can fire me I don't care, but I will tell him how I feel (P10).

\section{A lack of involvement in family activities}

This category was described by dishonesty with family about true feelings, lack of family involvement during the period of recovery from the injury and being seen as abnormal by the family. One participant indicated that he was used to doing everything for his family. However, now his family tended to exclude him as a result of his physical limitations. He said:

I want to do something, like he (son) is moving all his girlfriends furniture now, normally I would do it but they've taken over that role. Which eventually would have happened if I were a 65 year old, old man, but I am a 65 year old young man. I did everything, I was always me, the main man (P4).

\section{A loss of future aspiration and quality of life}

The participants in this study indicated that because of their injuries they could not fulfil the dreams that they aspired for themselves and their families. They felt that the brain injury resulted in severe functional limitations that limited them from reaching their goals and aspirations. Participants felt that it reduced their ability to participate in work and leisure activities, while others felt that it limited their socio economic status. One participant explained how his brain injury had prevented him from doing jobs that would have been financially rewarding. He said:

They asked me if I wanted a supervisor's job. So I said I'll take it, but if you take a supervisor's job you must be there $24 / 7$ on the construction site and they work now only abroad. No, I can't go abroad now. I mean the structures you get abroad, it's heavy, high up in the air, I know what you get...(P6).

One participant explained how the accident prevented him from obtaining his diploma. He said

The one problem is that I didn't finish maths because I had the accident right before that. So I didn't get my national diploma in cartography(P2). 


\section{A loss of hope in the occupational roles}

This category was described by a loss of hope in the worker role, loss of promotional opportunities and how stage of life affected the ability to complete work related courses. One participant indicated that since the brain injury, he experienced problems with his balance. As a result he could not engage in his occupation as a brick layer, he lost hope in his role as a worker. He said:

We need to climb on top of the scaffolding. It would be very hard for me to climb. I was fearful because I was off balance. It was difficult to use the step ladder because the right one (leg) is not much strong $\left(\mathrm{P}_{7}\right)$.

Another participant indicated that he enjoyed running. He could no longer participate in these leisure occupations. He said:

I could run from here to Cape Town without losing my breath and I don't have to jog everyday that's just the way my body was. Like sitting here, all of the things you know are all incredibly debilitating. A young 65 that expected to do all of the things I used to be able to do, till doomsday ( $\left.\mathrm{P}_{4}\right)$.

\section{Barriers- theme two: Uncertainty about the future}

The theme described the participant's experiences of not being prepared for the future. This unpreparedness resulted in feelings of uneasiness about planning ahead owing to their physical and cognitive limitations. The theme uncertainty about the future is categorized by fear of the unknown, being underestimated by society, fear of resumption of occupational roles and the perception of being a burden to society. Finally the theme is described by the exclusion from occupational activities and a loss of meaningful occupation.

\section{Fear of the unknown}

This category represents the participants' experience of fear that they had particularly in relation to their socio economic status and their functional abilities. These experiences were categorized by descriptions of the participant's fear of unemployment, fear of not being accepted by his or her family and the uncertainty of socio-economic conditions. The participants in this study had a fear of being unemployed after the brain injury. This fear manifested itself in a form of anxiety. The participants expressed their anxiety when they were unemployed after the accident. One participant indicated that he became worried when it became obvious that he was struggling to find employment.

I started to get anxious because I only got a job after a year and ten months after the accident $\left(\mathrm{P}_{5}\right)$. 
Another participant indicated that he becomes frustrated with the fact that he could not provide his wife with a good quality of life. This frustration stems from a sense of insecurity in terms of his work. He said:

I tell my wife, I just want to die, I don't feel like living anymore. It just upsets me that I can't give her what I would love to give her. I know money's not everything but still. I've given my wife a nice home, but there's other stuff like eating out, like my brother they can eat out, they ate out last night. I can't even do that (P8).

One participant indicated that he particularly feared his family turning their back on him. He said:

Anyway the big thing is your family, the people that pull together, because they could have just said ja his gonna be a retard, or a cripple or whatever. They definitely would have put me or whoever the accident victim was, into that category and you go with the flow (P4).

\section{Fear of being underestimated by society}

The participants feared being underestimated by society owing to their physical and cognitive limitations. In this category the participants' feelings are described by a sense of being used for one's skill, frustration owing to being handled like a child and not taken seriously and being underestimated. The participants in this study were of the opinion that society underestimated them particularly when it came to general community activities and work tasks. Participants described their feelings of isolation and the impact of cultural expectations of gendered roles on the person. One participant indicated that:

Prepare the family that they have to let the person believe that they are as normal as possible, You don't want to feel like people are whispering behind your back you know (P4.)

Participants described their feelings of isolation and the impact of cultural expectations of gendered roles on the person. One participant indicated that his friends were underestimating his ability, he took offense to this because in the Xhosa culture a man should not be disrespected. He said:

I could see the guys will no longer rely on me... I could see these guys are no longer the same to me. They underestimate $\mathrm{me}\left(\mathrm{P}_{7}\right)$.

\section{Perception of being a burden to society}

This category described the participants' perception of being a burden to society. The participants felt that by not being able to resume previous roles, that society was overlooking them. The category was also described by a strong need for independence in all aspects of life and stigma related to the brain injury. One participant felt that he was 
being a burden to society by constantly depending on a disability grant. He felt that he did not want to be dependent on others. He said:

And I will work for my children, you understand, and I did not apply for another disability grant again. It was in me, in me, I feel that you must work for yourself when you are young. Your mother and father teaches you, that you must not be dependent on others, you understand, that is why I don't want to be dependent on others (P10).

Some of the participants were of the opinion that there was a stigma related to having a brain injury. They were of the opinion that people saw them as abnormal or were scared of them. One participant said:

I am aware that it's head trauma and people are scared of people with head injuries. They go off the rails and things (P2).

\section{The loss of meaningful occupation}

The category highlighted that that participants experienced a loss of quality of life after the brain injury due to their non-involvement in meaningful self care, work and leisure occupations. The category also described how the participants were forced to engage in work occupations that were not meaningful to them because of poor socio economic conditions. One participant indicated that the job that his employer and doctor prevented him from resuming his previous job as a security gate operator. He felt that his job was not complicated, yet the employer and doctor prevented him from resuming employment despite him being functionally ready. As a result he was forced to look for alternative employment regardless of whether it was meaningful or not. He said:

I only opened the gates and maybe at night I patrolled the place. When I returned to work after the accident, they (employer) told me that I can't work there because my doctor had told them so. So, I went to look for another job and I found another job (P10).

One participant indicated that the job that he participated in was not meaningful to him as he earned too little money which affected his quality of life. He said:

Upset, I think about it all the time. I just think I'll never get a job where I can get decent money. So I just live day to day. Not like my brother who... they can do what they want you know, like my twin brother he just spends money left, right and centre. I mean he can work on a Sunday and he earns R5000 (P8).

\section{Facilitators- theme three: Participation in occupation enables growth}

This theme describes the notion that participation in occupation enables growth and recovery. The growth is interpreted as the participants' ability to regain independence and engage in previous activities. This theme is characterized by occupation as a basic 
need, having balanced activities, exclusion from occupational activities, occupational alienation and occupational adaptation.

\section{Occupation as a basic need}

The category described the participants' perception of work as a means to survive and that involvement in occupation facilitated a healthy mind. The category also described that non engagement in leisure occupation was mentally disabling and that participation in occupation was integral to physical and psychological health. In the initial stages of the brain injury, participants often could not engage in occupational tasks as they did before the injury and this caused them to become motivated in order to become productive in activity. One participant indicated that he was the only bread winner and he had to resume the worker role in order to supplement his income. He said:

I am the only one, that is a breadwinner, so I need to look around for part time work in order to survive $\left(\mathrm{P}_{3}\right)$.

Another participant said:

I can't live like this for the rest of my life... that's why I sommer (immediately) rolled from the bed in hospital because I couldn't I'm not used to it. I like to be independent and not to depend on other people (P6).

Another participant felt that engagement in leisure occupation was essential for his health, he became frustrated when he could not resume his previous leisure activities. He said:

I could run from here to Cape Town without losing my breath and I don't have to jog everyday that's just the way my body was. Like sitting here, all of the things you know are all incredibly debilitating. A young 65 that expected to do all of the things I used to be able to do, till doomsday ( $\left.\mathrm{P}_{4}\right)$.

\section{Having balanced occupations}

In this study the participants explained the importance of having balance in occupational routines. One participant indicated that he works hard during the week and that he continues to participate in leisure time activities such walking on the beach.

We work till we done on Tuesday so Wednesdays is bit more relaxed. I got some of, part of the people at work to go and join me in the big walk on Sunday (P2).

I didn't give up on my sport, I mean, I won't go do a full contact sport, and the surfing thing was... I mean I like surfing but the body boarding was fun but not the same (P2). 


\section{Occupational adaptation}

In the current study adaptation of workplace and home routines was seen as a mechanism in which they maintained their worker roles. Some participants mentioned that their work and home tasks were adapted after the injury in order to accommodate their functional limitations. One participant indicated that he adapted to his daily routines by actively helping himself. He described to the participant that he had to adapt the manner in which he opened a jar in order to get sugar. He said

How can I turn my hand, the tin is round and I can't take it like this, then I take it like this (shows the interviewer). I bring it close to my arm then I hold it like this, thereafter I take out my spoon of sugar. I do the same with the coffee tin (P1).

Another participant explained that despite him not being able to actively engage in work tasks, he adapted his role from physically doing the work to supervising others. He said:

I do some private work, oh Ja I build carports for people. Ja I manage it because I just tell my brother and his son or my two sons, do that do that I explain to them how to do it (P6).

Due to their changed functional ability, they had to either seek new ways of doing things or accept routines that had been put in place by others. One participant said that it took him some time to accept the way his family managed his business. He said:

I just slowly, slowly take my position back it took a long time to get that back. It's just difficult to explain you know a huge strain, you come down stairs after being away for two years and everybody's doing things their way. And this is my bloody business, I built it and it took me a long time to accept that, I had to accept the way they run it, it's been 4, 5 years now and I've only really been active in the business for a year ( $\mathrm{P} 4)$.

\section{Discussion}

The barriers within this study consisted of the participants' experience and perception of loss of their physical, cognitive and functional abilities. This loss was also interpreted in terms of their loss of family involvement, a loss of future aspiration and a loss of hope in occupational roles. Other barriers within the context of this study included a lack of preparedness for the future, fear of being underestimated by society and the perception of being a burden to society. These fears resulted in feelings of uneasiness about planning ahead owing to their physical and cognitive limitations.

The barriers identified in this study clearly impacted on the participant's ability to return to work. Individuals with brain injury tend to suffer multiple functional limitations. The physical losses experienced by the participants in this study could be attributed to abnormal muscle tone, muscle weakness, abnormal reflexes and spasticity after the injury [8]. Cognitive disability is viewed as the reduced efficiency, pace and persistency of thinking required to engage in occupation or a failure to adapt to novel or problematic

\section{http://repository.uwc.ac.za}


situations [8]. In the current study cognitive losses impacted on the participant's ability to engage in activity, to such an extent that they struggled to resume their previous roles. In a study conducted by McCarthy, Dikmen, Langlois, Selassie, Gu and Horner [26] they used the 36 Item Short Form Health Survey (SF-36) to measure psychosocial health on 7612 participants who was diagnosed with a brain injury. Their results indicated that $29 \%$ of the sample perceived themselves to have poor psychosocial health and that subjects who had difficulty with activities of daily living (ADL) were significantly more likely to have poor psychosocial health. This supported the results of the current study in that the majority of the participants who experienced difficulties with ADL also reported psychosocial limitations.

It is documented in the literature that the loss of the ability to live independently in the community reinforces feelings of dependence and decreased personal control [8]. The fact that these individuals' families ignored them and stereotyped their functional ability caused them to lose their occupational identity. Kielhofner [27] described occupational identity as a sense of who one is and wishes to become as an occupational being. It starts with the self knowledge of our capacities and interests from past experiences and extends to constructing a vision for the future [27]. Within the context of the current study the participants experienced a loss of occupational identity, example, the perception of a sense of loss reinforced their uncertainty about the future. In a study conducted by Gutman [28] she found that her participants also reflected feelings of disappointment and depression due to factors such as the loss of work and not being able to meet personal role expectations. In the current study the participants often became fearful when the deficits in their various occupational roles such as worker, mother, father and caregiver became apparent. Gutman [28] further indicated that the individual with the brain injury felt victimized by society, in that they were often used by family members for their wealth. It could be argued that individuals with brain injury were viewed as being vulnerable. In the current study the participants felt as if society underestimated them by treating them like children and disrespecting their abilities. This often caused the individual with the brain injury to lose confidence in him or herself.

The facilitators within the context of this study included the participant's basic need to participate in occupation that facilitated growth and recovery after the brain injury. Other facilitators included the brain injured individual's need to have a balance of occupations and their ability to adapt to their occupations.

Wilcock [29] indicates that occupations are innate and humans participate in occupations for the purpose of their health and for survival. This would appear to support the participants' perceptions of participation in diverse occupations as being essential to recovery and eventual return to work. Wilcock [30] defines occupational balance as a regular mix of physical, mental, social, spiritual and rest occupations that provide an overall feeling of well being. From the above definition it could be argued that a healthy balance between self care, work and leisure activities is essential to achieve 
occupational balance. The participants in the current study highlighted the importance of engaging in leisure and work related activities. Many of them alluded to an improved quality of life due to engagement in both leisure and work related occupations after the injury. However the lack of participation in meaningful leisure and work related activities caused feelings of exclusion and occupational alienation. Occupational alienation is described by prolonged experiences of disconnectedness, isolation, emptiness, lack of sense of identity or a sense of meaningfulness [31]. It was evident in the current study that participants experienced occupational alienation as they felt isolated from society and that they lost meaning in their work role.

The participants in the current study often referred to their experiences of adapting to their various occupational roles. Adaptation was seen as an internal mechanism that enabled the individual with the brain injury to adapt the manner in which they performed a task or work routine. One participant indicated that he had to be honest with his employer about his abilities so that they could adapt his work environment to his functional ability after the injury. The literature highlights that adaptation is an internal process by which people respond to a demand for change [32]. This is achieved when the person incorporates the new skills and habits into their daily occupational performance [32].

\section{Study limitations}

The results of the study are limited by the inherent nature of qualitative research in which the findings cannot be generalized to the population. Furthermore even though the researcher tried to include the more females in the study, it was extremely difficult to obtain females that met the inclusion criteria of the study.

\section{Implications for clinicians}

The clinician should utilize a client centered approach in the planning and implementation of treatment. Clinicians should get an in depth perspective of the barriers that individuals with the brain injury experiences or perceives when returning to work. Although some of these perspectives may not directly be related to the return to work process, example, the client's experience of loss of family involvement or their fears of being a burden to society, it has an impact on the client's return to work motivation. Clinicians should actively utilize the facilitators that individuals with brain injury experience, example, advocate active engagement not only in work related tasks but also leisure or ADL tasks. Participation in ADL and leisure tasks could be a stepping stone for eventual engagement in work related tasks. Clinicians needs to realize that a brain injury is a multifaceted condition that requires holistic intervention even though a client may show no emotional or cognitive limitations, it is pertinent that the clinician still consider the client's emotional and cognitive status. Finally utilizing the client's opinion about how work tasks or routines could be adapted to suit their needs should be a priority for the treating health professional. Of the ten participants interviewed only three of them received occupational therapy intervention and none of the participants rehabilitation had a focus on return to work. It could be argued that the occupational 
therapists (including other health professionals) should focus on the client's return to a worker role during intervention.

\section{Conclusion}

In conclusion theme one and theme two presented the participant's losses and fears that they experienced which influenced the return to work process. Theme three indicated that participation in occupation facilitated the participants' return to their worker roles. The flow diagram below (see Fig. 1) indicates that theme one and two could be seen as barriers and theme three as facilitators that the participants experienced. These barriers and facilitators influence the adaptation process of the individual in a positive and/or negative manner. The study highlighted that the functional deficits related to the condition was multifaceted and required a client centred holistic work integrative approach.

\section{Acknowledgement}

This project was supported by the University of the Western Cape and the Cannon Collins Educational trust of South Africa. 


\section{References}

[1] S.A. Gutman, Traumatic brain injury, in: Occupational Therapy: Practice skills for physical dysfunction, $5^{\text {th }}$ edition, L.W. Pedretti and M.B. Early, eds., Mosby, St Louis, 2001.

[2] L. Zhang, B.C. Abreu, B. Massel, R.S. Scheibel, C.H. Christiansen, N. Huddleston and K.J. Ottenbacher, Virtual reality in the assessment of selected cognitive function after brain injury, American Journal of Physical Medicine 80 (2001), 597-604.

[3] S. Philpott and P. McLaren, Disability, South African Health Review. Health Systems Trust, Durban, 1997.

[4] P. Jansen, Vocational rehabilitation following brain damage: alternative approaches and functional models of retraining, South African Journal of Occupational Therapy 24(2) (1994), 20-24.

[5] Tygerberg Hospital Work Assessment Unit. (2004). Available: On request from acgoosen@pgwc.gov.za

[6] Y. Ben-Yishay, S.M. Silver, E. Piatsetsky and J. Rattok, Relationship between employability and vocational outcome after holistic cognitive rehabilitation, Journal of Head Trauma Rehabilitation 2 (1987), 35-48.

[7] B.E. Murdoch and D.G Theodoros, Traumatic brain injury: associated speech, language and swallowing disorders, Singular Thomson Learning, San Diego, CA, 2001.

[8] M. Tipton-Burton, R. McLaughlin and J. Englander, Traumatic brain injury, in: Pedretti's Occupational Therapy: Practise skills for physical dysfunction, $6^{\text {th }}$ edition, H.M. Pendleton and W. Schultz-Krohn, eds., Elsevier Mosby, Philadelphia, 2005.

[9] B. Johnstone, D. Mount and L.H. Schopp. Financial and vocational outcomes 1 year after traumatic brain injury, Archives of Physical Medicine Rehabilitation 84 (2003), 238-241.

[10] Statistics South Africa. (2005). South African Mortality Rates: Deaths where a head injury was recorded. Statistics report of South African mortality rates from 1997-2002. [Online] Available: http://www.statssa.gov.za [Accessed: 04/05/o5]. Available: on request from elsiem@statssa.gov.za.

[11] Tygerberg Hospital Brain Injury Statistics. (2005). Available: On request from pmacgregor@pgwc.gov.za.

[12] South African Department of Labour. (2003). Compensation for occupational injuries and diseases act, 1993. Statistics report of the compensation fund. Table 5 of 1996-1998. [Online] Available: http://www.statsa.gov.za [Accessed: 01/o8/2003].

[13] S.S. Lee, N.J. Powell and S. Esdaile, A functional model of cognitive rehabilitation in occupational therapy, Canadian Journal of Occupational Therapy 68(1) (2001), 41-50.

[14] G. Blundon and E. Smits, Cognitive rehabilitation: A pilot survey of the therapeutic modalities used by Canadian occupational therapists with survivors of traumatic brain injury, Canadian Journal of Occupational Therapy 67(3) (2000), 184-196. 
[15] J.A. Cook and J. Burke, (2002). Public policy and employment of people with disabilities: exploring new paradigms, Behavioural Sciences and the Law 20(6) (2002), 541-557.

[16] C.J. Jones, D.V. Perkins and D.L. Born, (2001). Predicting work outcomes and service use in supported employment service for persons with psychiatric disabilities, Psychiatric Rehabilitation Journal 25(1) (2001), 53-59.

[17] P. Wehman, M. West, J. Kregel, P. Sherron and J.S. Kreutzer, Return to work for persons with severe traumatic brain injury: A data based approach to programme development, Journal of Head Trauma Rehabilitation 10 (1995), 27-39.

[18] U. Johansson and K. Tham, The meaning of work after acquired brain injury, The American Journal of Occupational Therapy 60 (2006), 60-69.

[19] A.R. Darragh, P.L. Sample and S.R. Krieger, Tears in my eyes: Cause somebody finally understood: Client perceptions of practitioners following brain injury, American journal of occupational therapy 55(2) (2001), 191-199.

[20] J.W. Creswell, Research design: qualitative and quantitative and mixed methods approaches, $2^{\text {nd }}$ edition, Sage Publica tions, Thousand Oaks, 2003.

[21] D.M. Bailey, Research for the Health Professional: A Practical Guide, ${ }_{2}^{\text {nd }}$ edition, F.A. Davis Company, Philadelphia, 1997.

[22] A. Fontana and J.H. Frey, Interviewing the art of science, in: Handbook of qualitative research, N.K. Denzin and Y.S Lincoln, eds., Sage, Thousand Oaks, CA, 1994.

[23] D.L. Rudman and S. Moll, In-depth interviews, in: Qualitative Research in Occupational Therapy, J.V. Cook, ed., Delmar, Australia, 2001.

[24] J.N. Morse and P.A. Field, Nursing research: Application of qualitative approaches, $2^{\text {nd }}$ edition, Chapman and Hill, London, 2002.

[25] M.E. Duffy, Methodological triangulation, in: Practical Research: Planning and Design, $5^{\text {th }}$ edition, P.D. Leedy, ed., Macmillan, New York, 1993.

[26] L. McCarthy, S.S. Dikmen, J.A. Langlois, A.W. Selassie,

J.K. Gu and M.D. Horner, Self reported psychosocial health among adults with traumatic brain injury, Archives of Physical Medicine Rehabilitation 87 (2006), 953-961.

[27] G. Kielhofner, A model of human occupation: theory and application, Baltimore, Lippincott Williams \& Wilkins, 2002.

[28] A. Gutman, Brain injury and gender role strain: rebuilding adult lifestyles after injury, Occupational Therapy in Mental Health 15(3/4) (2000), 1-149.

[29] A.A. Wilcock, A theory of the human need for occupation, Journal of Occupational Science: Australia 11 (1993), 17-24. [30] A. Wilcock, Relationship of occupations to health and well being, in: Occupational therapy: Performance, Participation and Well being, $3^{\text {rd }}$ edition C.H Christiansen, C.M Baum and J. Bass-Haugen, eds., Slack incorporated, Thorofare, New Jersey, 2005.

[31] E. Townsend and A.A. Wilcock, Occupational justice and Client-centred practice: A dialogue in progress, Canadian Journal of Occupational Therapy 71(2) (2004), 75-87. 
[32] P. Moyers, Introduction to occupation based practise, in: Occupational therapy: Performance, Participation \& Well being, $3^{\text {rd }}$ edition, C.H Christiansen, C.M Baum and J. Bass-Haugen, eds., Slack incorporated, Thorofare New Jersey, 2005. 